\title{
Genetic aspects of lambing difficulty in Scottish Blackface sheep
}

\section{J Ilska ${ }^{2,1}$, J Conington ${ }^{1}$, N Lambe}

${ }^{1}$ Scottish Agricultural College, Midlothian, United Kingdom, ${ }^{2}$ The University of Edinburgh, Midlothian, United Kingdom Email:jo.conington@sac.ac.uk

Introduction Lambing difficulty is one of the main causes of lamb losses. It can affect both lamb survival and maternal ability, which are being actively selected for in modern sheep breeding. The available literature concentrates on environmental factors affecting the ease of birth, with special attention given to birthweight and sex of the lamb, litter size and presentation. Previous studies reported that there is an intermediate optimum birth weight at which lambs are less prone to experience dystocia (Sawalha et al., 2007). Lamb birth weight is related to litter size, with singletons more likely to be too heavy, and lambs born in multiple litters more likely to be too light, to meet this optimum. The genetic basis to lambing ease was realised when breed differences in the occurrence of lambing difficulties were first reported (Grommers, 1985). The aim of this study was to evaluate the genetic component of lambing difficulty in Scottish Blackface sheep and to explore key environmental components affecting the occurrence of dystocia in this population.

Material and methods Data on lambing difficulty (LDIFF) from 8201 lambs, born between 2001 and 2007 from 2,344 Blackface ewes on two SAC hill farms, was used for this study. LDIFF scores and the proportion of lambings that fell into each category were reported from a similar data set by Lambe et al., (2006), using a 0-7 scale, where $0=$ no difficulty, $1=$ normal presentation but assisted, $2=1$ leg back, $3=2$ legs back, $4=$ head back, $5=$ back legs first, $6=$ breech, $7=2$ lambs together. The data were re-coded as a binary trait (ASSIST), with $0=$ no assistance and $1=$ assistance given. Significant environmental factors were investigated using multiple linear models in the statistical package 'R' (Venables and Smith, 2009). Multiple regression was used to examine the effects and interactions of gender, birth weight and whether lambs were born dead or alive (D/A) on ASSIST and LDIFF. ASReml (Gilmour et al, 2002) software was used for the genetic analyses (including heritability $\left(\mathrm{h}^{2}\right.$ ) estimates), using a sire (of lamb) model for the analyses for ASSIST and LDIFF, with fixed effects of age of dam (5 levels), birth rank (4 levels), farm (2 levels), D/A (2 levels), gender (2 levels), year of birth (7 levels), lamb birth weight and ewe pre-lambing condition score (covariates) and interactions among birth weight, gender and D/A. The analyses assumed binomial distribution and used a logit link function. To analyse LDIFF as a trait of the ewe $\left(\sigma_{\mathrm{a}}\right)$, the same fixed effects were fitted in an animal model, with random sire $\left(\sigma_{\mathrm{S}}\right.$; of lamb), common environment (c; litter effect) and repeatability (r; of dam) effects fitted.

Results The total percentage of lambings that were assisted was shown in Figure 1. In lambs born alive, males with birth wei६ female lambs of the same weight. This trend becomes reversed fc

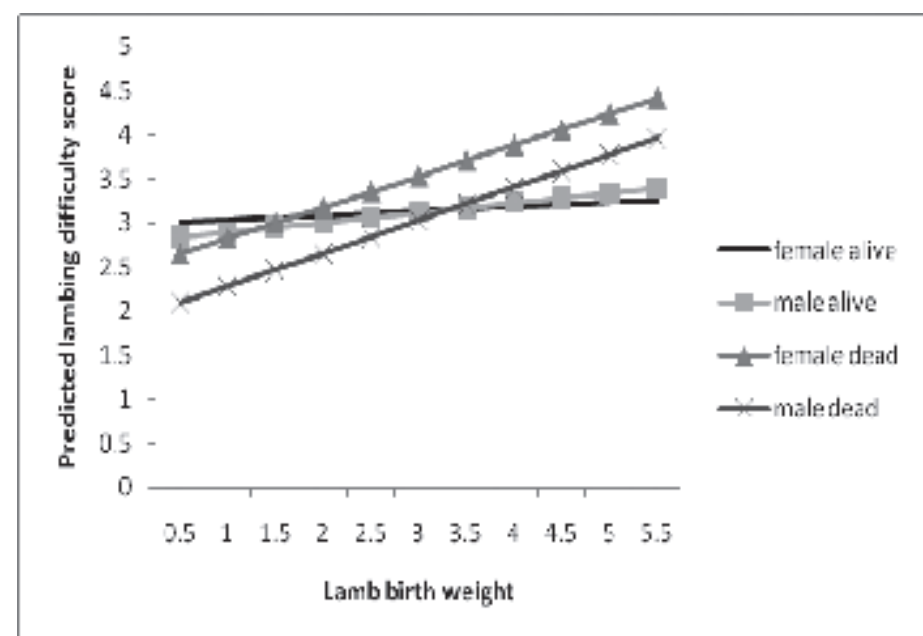

Table 1 Genetic properties

\begin{tabular}{lccc}
\hline \hline & & $\mathrm{h}^{2}$ & s.e. \\
\hline ASSIST (sire) & 0.380 & 0.088 \\
LDIFF (sire) & 0.084 & 0.018 \\
LDIFF & $\sigma_{\mathrm{a}}$ & 0.005 & 0.011 \\
& $\sigma_{\mathrm{S}}$ & 0.105 & 0.022 \\
& $\mathrm{c}$ & 0.177 & 0.016 \\
& $\mathrm{r}$ & 0.183 & 0.012 \\
\hline \hline
\end{tabular}

The estimate of heritability for the binomial analysis (AASIST) is moderate and higher than that for LDIFF. This is either due to the binomial methodology used or because the 0-7 category of LDIFF is not on a graded scale of severity. Most variation is attributed to nongenetic components of $\mathrm{c}$ and $\mathrm{r}$ for the animal model analyses.

Figure 1 Interactions of gender, birth weight and lambing difficulty score

Discussion The perception of male lambs experiencing more difficult births than female lambs reported in previous studies is justified only by the interaction described above. Binomial analyses for dystocia resulted in higher heritability estimates and would be the preferred method of analysis for the estimation of EBVs for dystocia in sheep.

Acknowledgements Defra, Scottish Government, EBLEX, HCC and QMS for funding, M. Steel, C. Brockie and A. McLaren for data collection.

\section{References}

Gilmour, A.R., Gogel, B.J., Cullis, B.R., Welham, S.J. and Thompson, R. 2002. ASReml Release 1.0. VSN International Ltd, Hemel Hempsted, UK.

Grommers, FJ, Elving, L, Van Eldik, P (1985). Animal Reproduction Science 9: 365 - 374

Lambe, N.R., Saurat, A., Conington, J., Bishop S.C. and Simm, G. 2006. Proc. BSAS, 27-29 March, Uni.York. P39

Sawalha, RM, Conington, J, Brotherstone, S, Villanueva, B 2007. Animal 1: $151-157$

Venables, W N, Smith, D M 2009 An Introduction to R. Version 2.9.1. http://cran.r-project.org/doc/manuals/R-intro.pdf 